\title{
Association of Adipocytokines: Resistin and Retinol Binding Protein-4 with Severity of Preeclampsia and Insulin Resistance
}

\author{
Abeer A. EL-Refai ${ }^{1,2}$, Sameer H. Fatani ${ }^{1}$, Hala F. M. Kamel ${ }^{1,3}{ }^{*}$ \\ ${ }^{1}$ Biochemistry Department, Faculty of medicine, Umm Al-Qura University (UQU), Makkha, KSA \\ ${ }^{2}$ Biochemistry Department, Faculty of medicine, Monufia University (MU), Shibeen Al-Koom, Egypt \\ ${ }^{3}$ Medical Biochemistry Department, Faculty of Medicine, Ain Shams University (ASU), Cairo, Egypt \\ *Corresponding author: kamelhala@msn.com
}

Received December 30, 2013; Revised April 23, 2014; Accepted May 27, 2014

\begin{abstract}
Dysregulation of maternal circulating adipocytokines has been implicated in several obstetrical syndromes including preeclampsia (PE). It has been suggested that adipocytokines provide a molecular link between metabolic derangements and inflammatory response in complicated pregnancies. We aimed in this study to evaluate the relationship between serum levels of Retinol binding protein-4 (RBP-4) and Resistin with clinical, anthropometric and metabolic parameters of PE. This study included 3 groups: group 1 included 50 pregnant females with PE, group 2 included 50 healthy pregnant females and group 3 included 50 healthy non-pregnant female as a control group. For all groups anthropometric and clinical measurements were performed. Serum RBP-4, resistin, insulin were measured by ELISA and Insulin resistance was calculated by Hemostasis model assessment index (HOMA-IR). Our results showed that serum RBP-4 and resistin concentrations were elevated in PE [39(33.2540.87) ug/ml] \& [61(23.5-91.87) ng/ml] compared to normal pregnancy [18.5(8-27.87) ug/ml] \& [25.5(12.7-49.12) $\mathrm{ng} / \mathrm{ml})$. Moreover, RBP4 but not resistin levels were elevated in severe cases relative to mild cases of PE. Serum levels of RBP4 showed positive significant correlation with [SBP $(r=0.38, p=0.001) \&$ DBP $(r=0.32, p=0.01)$ ] which are markers of severity. Fasting insulin was positively correlated with RBP-4 $(\mathrm{p}=0.04)$. By multiple linear regression analysis, serum RBP-4 levels were significantly and positively correlated with SBP $(\mathrm{P}=0.01)$, while markers of adiposity were not independently associated with resistin. Conclusion: RBP-4 and resistin were upregulated in PE, furthermore RBP-4 not resistin levels were independently associated with markers of severity of PE. However no clear relationship were observed between HOMA-IR with both RBP-4 and resistin and the role of Insulin resistance in PE was not clearly proved.
\end{abstract}

Keywords: preeclampsia, Resistin, Retinol binding protein-4, HOMA-IR

Cite This Article: Abeer A. EL-Refai, Sameer H. Fatani, and Hala F. M. Kamel, "Association of Adipocytokines: Resistin and Retinol Binding Protein-4 with Severity of Preeclampsia and Insulin Resistance." American Journal of Medical and Biological Research, vol. 2, no. 3 (2014): 76-82. doi: 10.12691/ajmbr-2-3-2.

\section{Introduction}

Preeclampsia is a multi-system specific disease of pregnancy, characterized by de-novo development of concurrent hypertension and proteinuria after 20th weeks of gestation and disappearance of all these abnormalities before the end of the 6th week postpartum [1]. The incidence of preeclampsia (PE) ranges from 3\% to 7\% for nulliparous and $1 \%$ to $3 \%$ for multiparas, it is a major contributor to fetal, neonatal and maternal morbidity and mortality [2]. The etiology and pathogenesis of PE still remains poorly understood. Recent breakthroughs have provided necessary insight in proposing the pathogenesis of PE as placental ischemia, excessive oxidative stress, in association with endothelial dysfunction, secondary to an initial defective placentation. Release of variable factors from the ischemic placenta into maternal plasma plays a central role in the ensuing endothelial dysfunction that is the most prominent feature of this disease, and manifested in various key organs of the mother causing the classic syndrome of PE [3]. Notably, preeclampsia, have been associated with maternal metabolic complications such as obesity, insulin resistance and dyslipidemia [4]. Many authors have demonstrated that dysregulation of Adipocyte-secreted factors called adipokines might play an important role in the pathogenesis of preeclampsia, because of their role in insulin resistance, lipid metabolism, atherosclerosis and low-grade systemic inflammation, therefore it is reasonable to suppose that adipokines may directly or indirectly influence the function of endothelial cells [5]. Resistin, an adipokine with a molecular weight of $12.5 \mathrm{kDa}$, also known as "adipocyte-derived secretory factor" (ADSF), has been linked with many facets of the metabolic syndrome, principally, obesity, insulin resistance and hyperlipidemia [6]. Human resistin is not a tissue specific protein and 
expression or secretion of this protein have been determined in muscle, pancreatic islets, mononuclear cells, macrophages, neutrophils, placenta and adipose tissue [7]. There is a controversy regarding the association among resistin, insulin-resistance, and obesity in humans [8,9]. Resistin is able to modulate the expression and activity of glucose transporter-1 (GLUT-1) in trophoblast cells, which is involved in the trans placental movement of glucose, contribute to resistin-induced insulin resistance and ensure the survival of the newborn [7]. However, studies in pregnancies with established PE have reported that maternal serum resistin concentrations may be increased, decreased, or not significantly different from those of normal controls [9]. RBP-4, a newly identified adipokine, secreted by adipocytes and the liver, the only known role of RBP 4 was that of retinol transport, until it has been shown to contribute to insulin resistance in several mouse models [10]. Serum RBP-4 concentration was elevated in insulin-resistant mice and humans with obesity and type-2 diabetes mellitus, normalization of serum RBP-4 concentration improve insulin resistance and glucose intolerance in mice. It also correlates with other components of the insulin resistance syndrome [11]. Circulating RBP-4 levels are positively associated with intima media thickness, an established parameter of atherosclerosis, thus it is a predictor of atherosclerosis and cardiovascular diseases [12].

\section{Subjects and Methods}

\subsection{Study Design and Samples}

This study was carried out from January 2012 to July 2013. Study protocol was approved by local ethical Committee of faculty of Medicine, Umm Al-Qura University, written informed consent was obtained from each subject.

\subsection{Study Groups and Inclusion Criteria}

Study included 150 females: 100 pregnant women as well as 50 age-matched non-pregnant healthy women were recruited as the control group with a mean age of $(30.85 \pm 5.08)$ years. Pregnant women were recruited at the Department of Gynecology and Obstetrics, Al-Noor Specialized hospital, Herra hospital (Makkah) and king Abd-el Aziz hospital (Al-Taif), Saudi Arabia. Pregnant females were categorized as Group 1: included 50 pregnant women with PE, their age ranged from (20-40) years with a mean of $(33.25 \pm 6.1)$ years. Group 2: included 50 gestational age-matched healthy pregnant women whose their age ranged from (20-42) years with a mean of (31.65 \pm 5.47$)$. PE was defined according to criteria recommended by guidelines of the American College of Obstetricians and Gynecologists (ACOG) as gestational hypertension $>140 \mathrm{mmHg}$ systolic and $>90 \mathrm{mmHg}$ diastolic on at least two occasions, at least 6 hrs apart accompanied by proteinuria $(\geq 1+$ by dipstick or $\geq 0.3 \mathrm{~g} / 24$ hrs) occurring after 20th weeks in pregnant women who were previously normotensive. The preeclampsia group was sub-classified into 2 groups, mild preeclampsia $(n=34)$ and severe preeclampsia $(n=16)$. Severe preeclampsia was diagnosed if one or more of the following criteria were present: blood pressure of 160/ $110 \mathrm{mmHg}$ or higher, excretion of $5 \mathrm{~g}$ or more of protein in a 24-hrs urine sample or urine dipstick of $3+$ or $4+$ in a random urine sample, oliguria of less than $500 \mathrm{ml}$ in 24 hrs, pulmonary edema or cyanosis, visual or cerebral disturbance, impaired liver function, thrombocytopenia and HELLP syndrome. Patients with preeclampsia who were not met that criteria of severe preeclampsia were diagnosed with mild preeclampsia.

\subsection{Clinical and Anthropometric Measures}

All participants were subjected to certain detailed questioner involved (personal, medical and family history), through general and abdominal examination, arterial blood pressure, body mass index (BMI) were calculated according to the equation: BMI = [(Weight $) /$ (Height $\left.)^{2}\right]$. Calculated BMI was aaccording to the pre-pregnancy BMI considering normal weight (BMI $<25 \mathrm{~kg} / \mathrm{m}^{2}$ ) and overweight/obese (BMI $\geq 25 \mathrm{~kg} / \mathrm{m}^{2}$ ) women.

\subsection{Sample Collection and Determination of Insulin, RBP4 and Resistin}

From all subjects Five milliliters of venous blood were collected after 12 hours over night fasting under complete aseptic precautions and transferred into a dry sterile centrifuge tube, the whole blood was allowed to clot at $37^{\circ} \mathrm{C}$ then centrifuge for $10 \mathrm{~min}$ at 4000 r.p.m. The clear supernatant serum was separated from the clot and kept frozen at $-20^{\circ} \mathrm{C}$ for subsequent ELISA assay of insulin, resistin and RBP-4.

\subsubsection{Determination of Insulin}

Assay of maternal insulin concentrations were performed using a commercially available enzyme-linked immunosorbent assay (ELISA) kit supplied by (DRG, $\mathrm{GmbH}$, Germany), according to the manufacture instructions [13]. Homeostasis model assessment-insulin resistance index (HOMA-IR): was calculated using the equation: HOMA-IR = fasting glucose $(\mathrm{mg} / \mathrm{dl})$. fasting insulin $(\mu \mathrm{U} / \mathrm{mL}) / 405$ [14].

\subsubsection{Determination of Resistin}

Maternal resistin concentrations were measured using (ELISA) kit supplied by (Assay Pro, Missouri, USA, Catalogue no. ER1001-1), according to the manufacture instructions. Concentrations of the unknown diluted samples were determined using the instructed standard curve and then multiplied by the dilution factor (1:5) to get the actual amount of resistin in the original serum [15].

\subsubsection{Determination of RBP-4}

RBP-4 concentrations were measured using a commercially available (ELISA) kit supplied by (Assay Pro, Missouri, USA, Catalogue no. ER3005-1), according to the manufacture instructions. Concentrations of the unknown diluted samples were determined using the instructed standard curve and multiplied by the dilution factor $(1: 1000)$ to get the actual concentration of RBP-4 [16].

\subsection{Statistical Analysis}

Statistical analysis was performed using Statistical Package for the Social Sciences (SPSS), version 16.0 for 
Windows (SPSS Inc., Chicago, IL, USA).Descriptive statistics in the form of mean $\pm S D$ were calculated for parametric data. On the other hand, non-parametric data were expressed as median and interquartile range (25-75th percentile). Comparisons between groups were done using the Student's t test in case of normally distributed data, and Mann-Whitney-U test was used in case of skewed data. The correlation between the variables were analyzed using Pearson's correlation (for normally distributed data), Spearrman's rank correlation (not- normally distributed data). To adjust the effects of covariates and identify independent relationships, multiple linear regression analyses were performed. $\mathrm{P}$ values $<0.05$ were considered significant, whereas $\mathrm{P}$ values $<0.01$ were considered highly significant.

\section{Results}

Demographic and clinical characters are summarized in (Table 1). (BMI) showed non-significant difference among all studied groups $(\mathrm{p}=0.35)$. As expected both Systolic blood pressure (SBP) $(\mathrm{P}=0.001)$ and diastolic blood pressure $(\mathrm{DBP})(\mathrm{P}=0.001)$ blood pressure, were significantly elevated in patients with $\mathrm{PE}$ as compared to both normal gestation and non-pregnant control groups, while a non-significant difference between normal gestation and non-pregnant control regarding SBP $(\mathrm{P}=0.45)$ and DBP, $(\mathrm{P}=0.69)$.

Table 1. demographic and clinical character of studied groups

\begin{tabular}{|c|c|c|c|c|}
\hline & & $\begin{array}{c}\text { Preeclampsia } \\
\text { (no 50) Mean } \\
\pm \text { SD }\end{array}$ & $\begin{array}{c}\text { Normal } \\
\text { gestation (no } \\
\text { 50) Mean } \\
\pm \text { SD }\end{array}$ & $\begin{array}{c}\text { Control group } \\
\text { (no 50) Mean } \\
\pm \text { SD }\end{array}$ \\
\hline \multicolumn{2}{|c|}{ Age (years) } & $33.25 \pm 6.1$ & $31.65 \pm 5.47$ & $30.85 \pm 5.08$ \\
\hline \multicolumn{2}{|c|}{ G age (weeks) } & $31.9 \pm 3.58$ & $34 \pm 3.26$ & $\begin{array}{ll}--- \\
\end{array}$ \\
\hline \multicolumn{2}{|c|}{ BMI $\left(\mathrm{kg} / \mathrm{m}^{2}\right)$} & $28.28 \pm 1.4$ & $27.06 \pm 2.04$ & $26.04 \pm 2.1$ \\
\hline \multirow{2}{*}{$\begin{array}{c}\text { Blood } \\
\text { pressure } \\
(\mathrm{mmHg})\end{array}$} & SBP & $151.1 \pm 25.8 * \circ$ & $117.4 \pm 7.5^{*}$ & $119.2 \pm 7.82^{\circ}$ \\
\hline & DBP & $93.4 \pm 8.45 * \circ$ & $80.15 \pm 7.7 *$ & $80.25 \pm 5.25^{\circ}$ \\
\hline
\end{tabular}

Table 2. statistical comparison of laboratory parameters among studied groups

\begin{tabular}{|c|c|c|c|}
\hline & $\begin{array}{l}\text { PE group }(n=50) \\
\text { Median (25th- } \\
\text { 75th percentile) }\end{array}$ & $\begin{array}{c}\text { Normal gestation } \\
(\mathrm{n}=50) \text { Median } \\
\text { (25th-75th } \\
\text { percentile) }\end{array}$ & $\begin{array}{l}\text { Control group } \\
(\mathrm{n}=50) \text { Median } \\
\text { (25th-75th } \\
\text { percentile) }\end{array}$ \\
\hline $\begin{array}{l}\text { insulin } \\
(\mathrm{uU} / \mathrm{ml})\end{array}$ & $24(12-29)^{\circ}$ & $15(7-20)$ & $9(8-14.5)^{\circ}$ \\
\hline $\begin{array}{l}\text { HOMA- } \\
\text { IR }\end{array}$ & $4.7(2.4-6.3)^{\circ}$ & $3.6(2.1-4.8)$ & $2.2(1.8-3.2)^{\circ}$ \\
\hline $\begin{array}{l}\text { Resistin } \\
\text { (ng/ml) }\end{array}$ & $61(23.5-91.87)^{\circ}$ & $25.5(12.7-49.12)$ & $\begin{array}{c}16.25(410.62- \\
30.25)^{\circ} \\
\end{array}$ \\
\hline $\begin{array}{l}\text { RBP-4 } \\
\text { (ug/ml) }\end{array}$ & $\begin{array}{c}39(33.25-40.87) \\
*\end{array}$ & $18.5(8-27.87) *$ & $24(7.6-41.87)$ \\
\hline
\end{tabular}

(RBP-4: retinol binding protein-4 HOMA-IR: homeostasis model assessment of insulin resistance, ${ }^{\circ} \mathrm{P}$ values $<0.01$ comparing $\mathrm{PE}$ with control \& (* P values $<0.01$ comparing $\mathrm{PE}$ with normal gestation)

Regarding Glucometabolic parameters, Fasting insulin levels were non-statistically significant differ in PE group as compared to healthy pregnant control group $(\mathrm{P}=0.09)$, accordingly HOMA-IR was non-significantly differ in PE group compared to healthy control pregnant group $(P=0.14)$, however fasting serum concentrations of insulin and HOMA-IR were significantly higher in $\mathrm{PE}$ as compared to non-pregnant control $(\mathrm{P}=0.001, \mathrm{P}=0.003)$ respectively (Table 2 ). Serum resistin was significantly higher in preeclampsia as compared to healthy pregnant and non-pregnant control $(\mathrm{P}=0.033, \mathrm{P}=0.001)$ (Figure 1$)$.

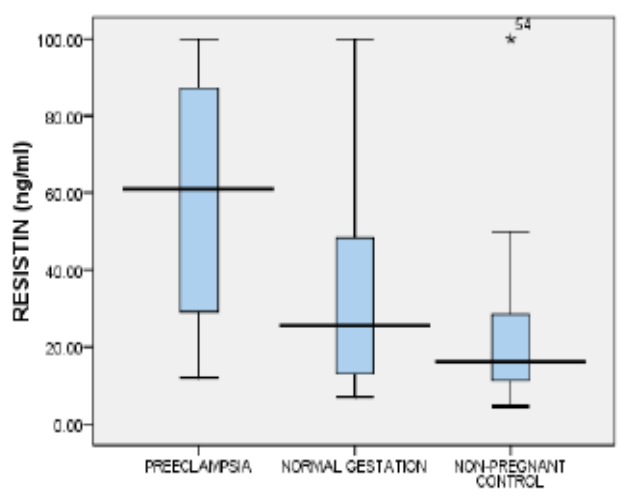

Figure 1. Resistin in all studied groups

Serum RBP-4 concentrations were significantly increased in subjects with PE [39(33.25-40.87) ug/ml] as compared to healthy pregnant [18.5(8-27.87) ug/ml)] $(\mathrm{P}=0.007)$ (Table 2). However, there was a non statistical significant difference between both preeclampsia [39(33.25-40.87) ug/ml] and healthy pregnant [18.5(827.87) $\mathrm{ug} / \mathrm{ml}$ )] as compared to non-pregnancy [24(7.641.87) ug/ml] regarding $\mathrm{RBP}-4 \quad(\mathrm{P}=0.7, \mathrm{P}=0.6)$ respectively (Table 2, Figure 1).

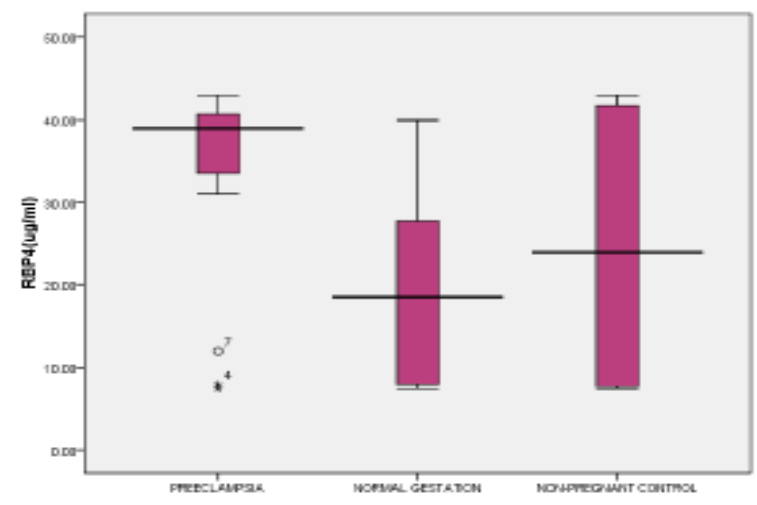

Figure 2. Serum RBP4 in all studied groups

Table 3. Maternal character among mild and severe cases of preeclamptic group

\begin{tabular}{|c|c|c|c|}
\hline & & $\begin{array}{l}\text { Mild preeclampsia } \\
\text { (no 34) Mean } \pm \text { SD }\end{array}$ & $\begin{array}{l}\text { Severe preeclampsia } \\
\text { (no 16) Mean } \pm \text { SD }\end{array}$ \\
\hline \multicolumn{2}{|c|}{ Age (years) } & $32.7 \pm 7.25$ & $34.5 \pm 1.6$ \\
\hline \multicolumn{2}{|c|}{ BMI (kg/m2) } & $27.7 \pm 0.82$ & $28.5 \pm 1.65$ \\
\hline \multicolumn{2}{|l|}{ Parity } & $1.9 \pm 0.26^{*}$ & $1.5 \pm 0.45^{*}$ \\
\hline \multicolumn{2}{|c|}{ G age (weeks) } & $33.4 \pm 3.25$ & $28.5 \pm 0.54$ \\
\hline \multirow{2}{*}{$\begin{array}{l}\text { Blood pressure } \\
(\mathrm{mmHg})\end{array}$} & SBP & $151.1 \pm 25.8 * *$ & $117.4 \pm 7.5^{* *}$ \\
\hline & DBP & $93.4 \pm 8.45^{* \circ}$ & $80.15 \pm 7.7 *$ \\
\hline
\end{tabular}

( $* \mathrm{P}$ values $<0.05$ significant, $(* * \mathrm{P}$ values $<0.01$ highly significant)

Furthermore, PE group was sub-classified into mild and severe cases (Table 3), 16 women had severe PE with a mean SBP and DBP of 180.6 $\pm 21.2 \mathrm{mmHg}$ and 102.5 \pm 8.2 $\mathrm{mmHg}$, respectively, While the 34 women had mild PE with mean SBP and DBP of $141.3 \pm 14.59 \mathrm{mmHg}$ and $90.7 \pm 4.4 \mathrm{mmHg}$, respectively. Patients developed severe $\mathrm{PE}$ had significantly higher SBP $(\mathrm{P}=0.004)$ and DBP $(\mathrm{P}=0.015)$ measures as compared to mild cases. Also, both gestational age $(\mathrm{p}=0.02)$ and parity $(\mathrm{p}=0.02)$ were significantly differ between mild and severe cases. However, other evaluated parameters (age and BMI) showed non-significant difference between severe and mild PE patients. 
Insulin and HOMA-IR were non-statistically significant differ in severe as compared to mild cases of preeclampsia $(\mathrm{P}=0.1, \mathrm{P}=0.15)$ respectively (Table 4$)$.

Table 4. statistical comparison of laboratory parameters among mild and severe cases of preeclamptic group

\begin{tabular}{|c|c|c|}
\hline & $\begin{array}{c}\text { Mild preeclampsia (no 34) } \\
\text { Median (25th-75th) }\end{array}$ & $\begin{array}{c}\text { Severe preeclampsia (no 16) } \\
\text { Median (25th-75th) }\end{array}$ \\
\hline $\begin{array}{c}\text { insulin } \\
\text { (uU/ml) }\end{array}$ & $15(11-29.2)$ & $28.5(28-29)$ \\
\hline $\begin{array}{c}\text { HOMA- } \\
\text { IR }\end{array}$ & $3.5(2.2-7.2)$ & $5.6(5.3-6.1)$ \\
\hline $\begin{array}{c}\text { Resistin } \\
\text { (ng/ml) }\end{array}$ & $61(41-98)$ & $46(17-75)$ \\
\hline $\begin{array}{c}\text { RBP-4 } \\
\text { (ug/ml) }\end{array}$ & $36(26.25-39.37)^{\circ}$ & $40.75(40.5-41)^{\circ}$ \\
\hline
\end{tabular}

(RBP-4: retinol binding protein-4 HOMA-IR: homeostasis model assessment of insulin resistance, ${ }^{\circ} \mathrm{P}$ values significant $<0.05$ )

Moreover, maternal serum RBP-4 was significantly increased in severe PE [40.75(40.5-41)] as compared to mild preeclampsia [36(26.25-39.37)] $(\mathrm{p}=0.01)$ (Table 4). Also both severe [40.75(40.5-41)] and mild PE [36(26.2539.37)] shows significant increase of RBP-4 as compared to normal gestation [18.5(8-27.8)] $(\mathrm{p}=0.001)(\mathrm{p}=0.02)$ (fig 2).However serum resistin showed no significant difference between mild and severe cases of $\mathrm{PE}(\mathrm{P}=0.17)$ (Table 4).

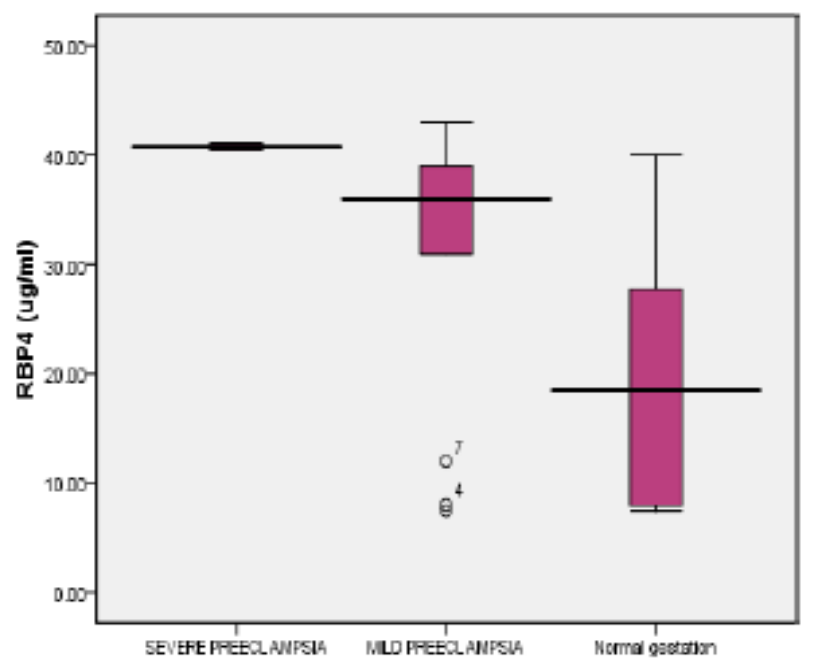

Figure 3. Serum RBP 4 in severe and mild preeclampsia in relation to normal gestation

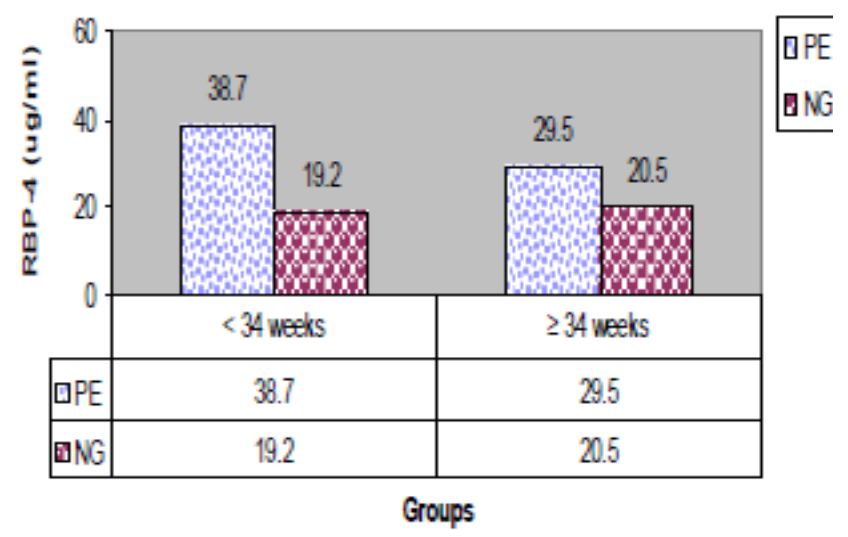

Figure 4. Serum RBP 4 in relation to gestation age ( $<34$ weeks $\& \geq 34$ weeks) in preeclampsia and normal gestation

In addition, both $\mathrm{PE}$ and normal gestation groups were classified according to gestational age into 2 groups, group $<34$ weeks $\& \geq 34$ weeks. In PE there was a non- significant difference in group $<34$ weeks $($ no=22) as compared to group $\geq 34$ weeks $(\mathrm{no}=28$ ) regarding $\mathrm{RBP}-4$ $(\mathrm{P}=0.14)$, also in group $\geq 34$ weeks there was a nonsignificant difference in $\mathrm{PE}$ as compared to normal gestation $(\mathrm{no}=21)$ regarding $\mathrm{RBP}-4(\mathrm{P}=0.15)$. However, $\mathrm{RBP}-4$ was significantly increased in $\mathrm{PE}$ as compared to normal gestation $(\mathrm{no}=29)$ in group $<34$ weeks $(\mathrm{P}=0.001)$ (Figure 4).

Bivariate analysis revealed that serum RBP4 levels were significantly and positively correlated with both SBP $(\mathrm{P}=0.0001)$, DBP $(\mathrm{P}=0.0001)$ (markers of severity), (Figure 5), also there was a significant positive correlation between RBP-4 and markers of Insulin resistance [fasting insulin in all cases $(p=0.04)$ ]. In contrast there was a significant negative correlation between RBP-4 and gestational age $(\mathrm{P}=0.007)$.

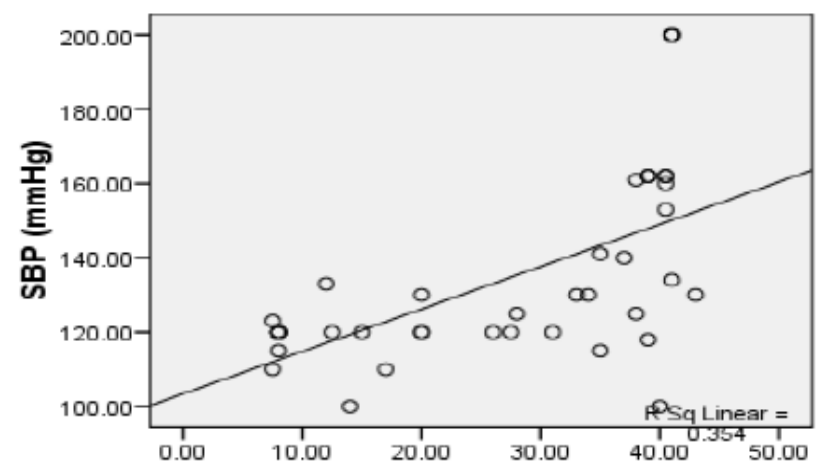

Figure 5. Serum RBP 4 in relation to systolic blood pressure among pregnant females

Serum levels of RBP4 showed non-significant correlation to BMI $(\mathrm{P}=0.8)$, HOMA-IR $(\mathrm{P}=0.1)$ and resistin $(\mathrm{P}=0.7)$ in pregnant women. Also, bivariate analysis showed significant positive correlation between resistin and markers of adiposity (weight and BMI) in all cases but not in pregnant females (Table 6), in contrast there were non-significant correlations between resistin and other assessed parameters. Furthermore in multiple linear regression analysis only SBP was independently associated with RBP-4 (dependent variable) among all cases $(F=20.8, R=0.59$, adjusted $R$ square $=0.33)$ (Table 7). However both weight and BMI were not independently associated with resistin (adjusted $\mathrm{R}=0.01, \mathrm{~F}=1.25$ ) (Table 8).

Table 5. Correlation between RBP-4 and variable markers among studied groups

\begin{tabular}{|c|c|c|c|c|}
\hline \multirow{2}{*}{} & \multicolumn{2}{|c|}{ All Studied groups $(\mathrm{n}=150)$} & \multicolumn{2}{c|}{ Pregnant women (n=100) } \\
\cline { 2 - 5 } & $\mathrm{r}$ & $\mathrm{P}$ & $\mathrm{r}$ & $\mathrm{P}$ \\
\hline Age & -0.07 & 0.5 & -0.003 & 0.97 \\
\hline G age & -0.33 & 0.036 & -0.41 & 0.007 \\
\hline Weight & 0.007 & 0.96 & 0.29 & 0.06 \\
\hline BMI & 0.05 & 0.69 & 0.06 & 0.8 \\
\hline SBP & 0.38 & 0.003 & 0.65 & $0.0001^{*}$ \\
\hline DBP & 0.32 & 0.011 & 0.61 & $0.0001^{*}$ \\
\hline F insulin & 0.26 & $0.04 *$ & 0.25 & 0.14 \\
\hline HOMA-IR & 0.22 & 0.07 & 0.23 & 0.11 \\
\hline Resistin & 0.13 & 0.29 & 0.003 & 0.79 \\
\hline
\end{tabular}

(GA: gestational age BMI: body mass index SBP: systolic blood pressure DBP: diastolic blood pressure, F insulin: fasting insulin HOMA-IR: homeostasis model assessment of insulin resistance) 
Table 6. Correlation between Resistin and variable markers among studied groups

\begin{tabular}{|c|c|c|c|c|}
\hline \multirow{2}{*}{} & \multicolumn{2}{|c|}{ All Studied groups $(\mathrm{n}=150)$} & \multicolumn{2}{c|}{ Pregnant women $(\mathrm{n}=100)$} \\
\cline { 2 - 5 } & $\mathrm{r}$ & $\mathrm{P}$ & $\mathrm{r}$ & $\mathrm{P}$ \\
\hline Age & 0.11 & 0.38 & -0.03 & 0.84 \\
\hline G age & 0.21 & 0.18 & 0.30 & 0.055 \\
\hline Weight & 0.36 & $0.005^{*}$ & 0.1 & 0.5 \\
\hline BMI & 0.25 & $0.047^{*}$ & -0.11 & 0.48 \\
\hline SBP & 0.09 & 0.47 & 0.09 & 0.65 \\
\hline DBP & 0.15 & 0.24 & 0.07 & 0.66 \\
\hline F insulin & 0.03 & 0.78 & -0.08 & 0.6 \\
\hline HOMA-IR & 0.03 & 0.82 & -0.03 & 0.84 \\
\hline
\end{tabular}

(GA: gestational age BMI: body mass index SBP: systolic blood pressure DBP: diastolic blood pressure, F insulin: fasting insulin HOMA-IR:

homeostasis model assessment of insulin resistance)

Table 7. stepwise linear regression analysis correlation between serum RBP-4 and clinical parameters (RBP-4 dependant variable)

\begin{tabular}{|c|c|c|}
\hline Independent variables & $\beta$ eta & P value \\
\hline SBP & 0.59 & 0.001 \\
\hline DBP & -0.169 & 0.59 \\
\hline G age & -0.109 & 0.45 \\
\hline
\end{tabular}

GA: gestational age SBP: systolic blood pressure DBP: diastolic blood pressure

Table 8. stepwise linear regression analysis correlation between serum Resistin and anthropometric parameters (resistin dependant variable)

\begin{tabular}{|c|c|c|}
\hline Independent variables & $\beta$ eta & P value \\
\hline Weight & 0.25 & 0.16 \\
\hline BMI & -0.22 & 0.21 \\
\hline
\end{tabular}

BMI: body mass index

\section{Discussion}

Previous studies have indicated that PE is associated with endothelial dysfunction, hypercoagulable state, metabolic abnormalities, an inflammatory response and atherosclerosis[17]. Increasing evidence has supported the diverse role of several adipokines such as leptin, adiponectin, and resistin in the pathogenesis of PE [18]. Resistin a novel peptide hormone that is specifically secreted by human adipocytes There is some evidence that the main source of resistin may be macrophages and monocytes, rather than adipose tissue [19]. Our study revealed a marked elevation of maternal serum resistin levels in women with PE compared to healthy pregnant control women. This comes in accordance with "Seol et al. [20]”, they demonstrated that serum resistin levels were significantly elevated in women with PE compared to normal pregnant women. Also, In case of PE, It was reported that increased levels of resistin were apparent from early pregnancy and that the levels are inversely related to the severity of PE [9]. By contrast our study revealed that resistin levels were increased in mild cases than severe cases of preeclampsia, but this difference was no statistically significant. However, increased resistin did not result from alterations in placental resistin expression, beside resistin mRNA levels in abdominal subcutaneous adipose tissues were similar between women with $\mathrm{PE}$ and normal pregnant women [21] This is supported by our finding of a lack of significant association between markers of adiposity and resistin in pregnant female also, both BMI and weight were not independently associated with serum resistin by linear regression analysis. The exact function of resistin in the pathophysiology of PE remains unclear, Lately it was reported that the elevated serum resistin levels might be associated with exaggerated insulin resistance via the extensive systemic inflammatory response in preeclampsia [20]. Extensive systemic inflammation is a well-known characteristic of PE [22], and monocyte activation is one of the associated features of systemic inflammation [23]. Monocytes may be the source of the increased serum resistin concentrations PE [24].

RBP-4 a novel adipokines that is up-regulated in insulin resistant states associated with obesity, also RBP-4 provokes insulin resistance. $\mathrm{RBP} 4$, similar to other adipokines, has also been linked to inflammation [25]. Our study revealed that Patients with $\mathrm{PE}$ had a significantly higher median maternal plasma concentration of RBP-4 as compared to women with a normal pregnancy. As regards serum RBP-4, the obtained results go hand in hand with, [26] who found that serum RBP-4 levels were increased in pregnant women with pregnancy induced hypertension compared with normal pregnancies. Also, our results come in lines with $[27,28]$ who reported that the maternal plasma RBP4 concentrations were higher among patients with PE than in those with a normal pregnancy. Our finding that $\mathrm{PE}$ is associated with higher circulating RBP-4 concentrations is in agreement with a study by "Atkinson et al., [29], in which a proteomic approach was used to identify novel biomarkers for preeclampsia. The authors found RBP-4 to be differentially up-regulated (2.1 fold-change) in the serum of patients with PE compared to matched healthy pregnant women. However, Stephan et al. [17] reported that RBP-4 levels showed non-significant difference between all patients with PE and normal controls. This discrepancy is attributed to that all the patients in their study were lean and showed early-onset cases of preeclampsia. In our study, preeclampsia group was categorized depending on both DBP and extent of proteinuria into 16 cases who had severe PE and 34 cases had mild PE. Furthermore, patients who had developed severe PE showed significantly higher serum levels of RBP-4 compared to those with mild PE. These results come in line with, "AlKholy et al. [30]” who reported higher RBP-4 serum levels in PE women compared to control subjects and also reported that RBP-4 showed significant difference in women with severe PE compared to both controls and those had mild PE. In support of such assumption, there were significant positive correlations between RBP-4 and markers of preeclampsia severity (SBP, DBP), Moreover, stepwise linear regression analysis showed that SBP was independently associated with RBP-4. these result comes in line with"Qi et al. [31]", they found that RBP-4 was also concerned with hypertension, also "Qi et al. and Ingelsson et al. [32,33]" reported that circulating RBP-4 has been associated with the number of the factors of metabolic syndrome specifically, circulating RBP-4 which has been found to increase in hypertriglyceridemia, low HDL-C, and hypertension. Furthermore, Chiba et al. [34] reported that serum RBP-4 levels were significantly related to SBP independently of age, sex, BMI, total cholesterol levels and estimated glomerular filtration rate. The obtained data suggested a participation of RBP-4 in the pathogenesis or modulation of PE. In addition, we found that the concentration of serum RBP4 in preclamptic patients with gestational age $<34$ weeks was significantly higher than in healthy pregnant women with gestational age $<34$ weeks. However, there was no 
significant difference in RBP-4 levels between preclamptic women with gestational age $\geq 34$ weeks and controls, In support of these results we found a significant negative correlation between RBP-4 concentrations with gestational age at blood collection (at the time of diagnosis of preeclampsia). Thus, the earlier the diagnosis, the higher were the maternal plasma RBP4 concentrations. This comes in line with Vaisbuch et al. [28] who reported that the RBP-4 concentrations had a significantly negative correlation with gestational age at time of blood collection in PE, not in normal gestation. This is pertinent since the timing of the diagnosis of $\mathrm{PE}$ is an important index of severity. In contrast Masuyama et al. [4] reported no significant differences in serum RBP-4 levels between all studied females with $\mathrm{PE}$ and controls, however the concentrations of serum RBP-4 in patients with late onset PE were significantly higher than in healthy pregnant women, but there were no significant difference in RBP-4 levels between women with early onset PE and controls. Different study population, methods and sample size may explain this discrepancy. The role played by RBP-4 in pathogenesis PE remains to be elucidated, RBP-4 appears to play an important role in insulin resistance that occurs during pregnancy and several previous studies documented such attribution between RBP4 and insulin resistance; $[10,35]$ They demonstrated that adipose tissuespecific (Glut4) knockout mice have increased serum levels of RBP4 and down regulation of GLUT4 in adipose tissue is an important feature of insulin resistance. The Compensatory hyperinsulinemia that serves to promote pathological actions of insulin, increased expression of vascular adhesion molecules, proliferation of vascular smooth muscle, increased expression of proinflammatory cytokines. These factors may shift the balance between vasodilator and vasoconstrictor actions of insulin and result in predisposition to hypertension in insulin resistant states. Clinical studies by Cheng and his colleagues [36] also reported that RBP-4 is positively related to insulin resistance especially in obese patients with impaired glucose tolerance and type 2 diabetics. This could be proved by significant positive association between RBP-4 and fasting insulin. However a clear relationship between HOMA-IR and RBP4 was not observed except in severe preeclampsia, most likely due to the small range of insulin sensitivity. Alternatively, we have to consider that we did not perform a direct measurement of insulin sensitivity in our study subjects, for example, by performing euglycemic hyperinsulinemic clamp therefore, it is possible that HOMA indexes might not be able to catch a fine difference in the degree of insulin sensitivity among these women. Several reports found a positive significant correlation between serum RBP-4 and markers of adiposity in all studied groups [27,30]. The lack of correlation between circulating RBP-4 concentrations and obesity-related parameters demonstrated in our study and those of others [17], leads to the suggestion that the liver, rather than adipose tissue, may be involved in regulating the circulating RBP-4 concentration. RBP-4 concentration might be a biomarker of nephropathy in type 2 diabetic subjects [37,38]. Beside the strong correlatio006E between kidney function and RBP-4 isoforms [39], it is possible that the impaired renal function that accompanies $\mathrm{PE}$, especially in its more severe form, may lead to decreased glomerular filtration rate and decreased excretion of RBP-4 in urine, thus serum RBP-4 may reflect the degree of renal affection in these preeclamptic women and may explain the positive significant correlation between serum RBP-4 and severity of PE (hypertension and proteinuria). To summarize we demonstrated that serum RBP-4 and resistin concentrations were up-regulated in PE relative to normal pregnancy, but they were comparable between normal pregnancy and non-pregnancy. Moreover, RBP-4 is elevated in severe cases relative to mild cases of PE. Furthermore, there was a significant positive correlation between RBP-4 concentrations and markers of preeclampsia severity (SBP, DBP).

\section{Conclusion}

The etiology and pathogenesis of $\mathrm{PE}$ still remains poorly understood. Many authors have demonstrated that dysregulation of adipokines might play an important role in the pathogenesis of PE. We aimed in this study to evaluate the relationship between serum levels of RBP-4 and Resistin with clinical, anthropometric and metabolic parameters of PE. Our results demonstrated the strong association of RBP-4 and resistin with the development of $\mathrm{PE}$ as both were significantly increased in PE, moreover RBP-4 levels were independently associated with markers of severity of PE. Interestingly we found that the earlier gestational age at which $\mathrm{PE}$ were diagnosed, the higher were the maternal plasma RBP-4 concentrations which is very important index of severity but the role of RBP-4 in pathogenesis of PE remains to be elucidated. The role of insulin resistance in preeclampsia was not clearly proved as no clear relationship between HOMA-IR and RBP-4 were observed.Further large scale analysis will be required to clarify the implication of both RBP-4 and resistin in PE and their association with various metabolic parameters involved in the pathophysiology of PE.

\section{Reference}

[1] Valensise H, Vasapollo B, Gagliardi G and Novelli GP. Early and late preeclampsia: "Two different maternal hemodynamic states in the latent phase of the disease". Hypertension: (2008) 52; 873-880.

[2] Carty D, Delles C and Dominiczak A. Preeclampsia and future maternal health. J Hypertens. (2010): 28; 1349-1355.

[3] Cudihy D and Lee V. The pathophysiology of pre-eclampsia. Journal of Obstetrics and Gynaecology. (2009): 29; 576-582.

[4] Masuyama H, Inou S and Hiramatsu Y. RBP-4 and insulin resistance in preeclampsia. Endocrine Journal. (2011): 58; 47-53.

[5] Miehle K, Stepan H and Fasshauer m. Leptin, adiponectin and other adipokines in gestational diabetes mellitus and pre-eclampsia: Clinical Endocrinology. (2012): 76; 2-11.

[6] Gao J, Chang Chua C, Chen Z, Wang H, Xu X and Hamdy R. Resistin, an adipocytokine, offers protection against acute myocardial infarction. J Mol Cell Cardiol (2007): 43; 601-9.

[7] Ippolito D, Tersigni C, Scambia G, and Di Simone N. Adipokines, an adipose tissue and placental product with biological functions during pregnancy. International Union of Biochemistry and Molecular Biology. (2012): 38; 14-23.

[8] Kusminski C, da Silva N, Creely S, Fisher F, Harte A, Baker A, Kumar S and McTernan P. The in vitro effects of resistin on the innate immune signaling pathway in isolated human subcutaneous adipocytes. J Clin endocrinol Metab. (2007): 92; 270-276.

[9] Nanda S, Poon L, Muhaisen M, Acosta I and Nicolaides K. Maternal serum resistin at 11 to 13 weeks' gestation in normal and pathological pregnancies. Metabolism clinical and experimental. (2012): 699-705. 
[10] Yang Q, Graham T and Mody N. Serum RBP-4 contributes to insulin resistance in obesity and type 2 diabetes. Nature. (2005): 436; 356-62.

[11] Ku Y, Han K, Ahn H, Kwon H, Koo B, Kim H and Min K. Resistance exercise did not alter intramuscular adipose tissue but reduced RBP-4 concentration in individuals with type 2 diabetes mellitus. Journal of International Medical Research. (2010): 38; 782-791.

[12] Graham T, Yang Q, Bluher M, Hammarstedt A, Ciaraldi T, Henry R, Wason C, Oberbach A, Jansson P, Smith U and Kahn B. RBP-4 and insulin resistance in lean, obese, and diabetic subjects. New England Journal of Medicine. (2011): 354; 2552-2563.

[13] Judzewitsch R, Pfeifer M, Best J, Beard J, Halter J and Porte D. Chronic Chlorpropamide therapy of noninsulin-dependent diabetes augments basal and stimulated insulin secretion by increasing islet sensitivity to glucose. J. Clin. End. and Metab. (1982): 55; 321328.

[14] Shirai K. Obesity as the core of the metabolic syndrome and the management of coronary heart disease. Curr. Med. Res. Opin. (2004): 20; 295-304.

[15] Schaffler A, Buchler C and Muller-Lander U. Identification of variables influencing resistin serum levels in patients with type 1 and type 2 diabetes mellitus. (2004): 36; 702-7.

[16] Mody N. Am. J. Physiol Endocrinol Metab. (2008): 294; 785-793.

[17] Stephan H, Ebert T, Schrey S, Reisenbüchler C, Blüher M, Stumvoll M, Kratzsch J, Tönnessen P, Faber R and Fasshauer M. Preliminary report: Serum levels of RBP-4 in preeclampsia. Metabolism. (2009): 58; 275-277.

[18] Zavalza-Gómez A, Anaya-Prado R, Rincón-Sánchez A and MoraMartínez J Adipokines and insulin resistance during pregnancy Diabetes Res Clin Pract. (2008): 80; 8-15.

[19] Patel L, Buckels A and Kinghorn I. Resistin is expressed in human macrophages and directly regulated by PPAR gamma activators. Biochem Biophys Res Commun. (2003): 300; 472-6.

[20] Seol H, Yeo M, Kim A, Lee E, and Kim H. Comparison of Serum Levels and the Placental Expression of Resistin Between Patients with Preeclampsia and Normal Pregnant Women. Hypertension in Pregnancy. (2010): 29; 310-317.

[21] Haugen F, Ranheim T, Harsem N, Lips E, Staff A and Drevon C. Increased plasma levels of adipokines in preeclampsia: relationship to placenta and adipose tissue gene expression. Am J Physiol Endocrinol Metab. (2006); 290; 326-333.

[22] Redman C and Sargent I. Latest advances in understanding preeclampsia. Science. (2005): 308; 1592-1594.

[23] Sibai B. Preeclampsia: an inflammatory syndrome? Am J Obstet Gynecol (2004): 191; 1061-1062

[24] Savage D, Sewter C, Klenk E, Segal D, Vidal-Puig A, Considine $\mathrm{R}$ and O'Rahilly S. Resistin/ Fizz3 expression in relation to obesity and peroxisome proliferator-activated receptorgamma action in humans. Diabetes. (2001): 50; 2199-2202.

[25] Yao-Borengasser A, Varma V, Bodles A, Rasouli N, Phanavanh B and Lee M. RBP-4 expression in humans: relationship to insulin resistance, inflammation, and response to pioglitazone. J Clin Endocrinol Metab. (2007); 92; 2590-2597.

[26] Inoue S, Takamoto N and Akahori. Elevated level of serum RBP-4 in pregnancy-induced hypertension. J Obstet Gynaecol Res. (2009): 35; 293-300.

[27] Shangguan X, Liu F, Wang H, He J and Dong M. Alterations in serum adipocyte fatty acid binding protein and retinol binding protein-4 in normal pregnancy and preeclampsia. Clinica Chimica Acta. (2009): 407; 58-61.

[28] Vaisbuch E, Romero R, Mazaki-Tovi S, Erez O and Kwon Kim S. RBP-4-A Novel Association with Early-Onset Preeclampsia. J Perinat Med. (2010): 38; 129-139.

[29] Atkinson K, Blumenstein M, Black M, Wu S, Kasabov N and Taylor R. An altered pattern of circulating apolipoprotein E3 isoforms is implicated in preeclampsia. J Lipid Res. (2009): 50; 71-80.

[30] Al-Kholy A, Abadier M, Rageh E and El-Kallaf H. Serum levels of placental growth factor and retinol-binding protein-4 in pregnancy-induced hypertensive women. ScienceJournal of American. (2010): 6:12.

[31] Solini A, Santini E, Madec S, Rossi C and Muscelli E. RBP-4 in women with untreated essential hypertension. Am J Hypertens. (2009): 22; 1001-6.

[32] Qi Q. Elevated RBP-4 levels are associated with metabolic syndrome in Chinese people. J. Clin. Endocrinol. Metab. (2007): 92; 4827-34.

[33] Ingelsson E, Sundstrom J, Melhus H, Michaelsson K, Berne C, Vasan R, Riserus U, Blomhoff R, Lind L and Arnlov J. Circulating retinol-binding protein 4 , cardiovascular risk factors and prevalent cardiovascular disease in elderly. Atherosclerosis. (2009): 206; 38-39.

[34] Chiba M, Saitoh S, Ohnishi H, Akasaka H, Mitsumata K, Furukawa T, and Shimamoto K. Associations of metabolic factors, especially serum (RBP4), with blood pressure in Japanese. Endocr J. (2010): 57: 811-7.

[35] Potenza M, Marasciulo F and Chieppa D. Insulin resistance in spontaneously hypertensive rats is associated with endothelial dysfunction characterized by imbalance between NO and ET-1 production. Am J Physiol Heart Circ Physiol. (2005): 289; 813822.

[36] Cheng $\mathrm{X}$ and Zhang H. Serum RBP-4 is positively related to insulin resistance in Chinese subjects with type 2 diabetes. Diabetes Res Clin Pract. (2009): 84 (1); 58-60.

[37] Henze A, Frey S, Raila J, Tepel M, Scholze A and Pfeiffer A. Evidence that kidney function but not type 2 diabetes determines RBP-4 serum levels. Diabetes. (2009): 57; 3323-3326.

[38] Cabre A, Lazaro I, Girona J, Manzanares A, Plana N and Heras M. RBP-4 as a plasma biomarker of renal dysfunction and cardiovascular disease. J Intern Med. (2007): 262; 496-503.

[39] Frey S, Henze A and Nagl B. Effect of renal replacement therapy on RBP-4 isoforms. Clin Chim Acta. (2009): 401; 46-50. 